\title{
Tech Companies and Social Justice: The Pandemic Race for Diversity, Access and Inclusion Moves Online
}

\author{
Dr. Monica Valentine \\ Assistant Professor, School of Public Administration, Kentucky State University, Kentucky, USA \\ *Correspondence: Dr. Monica Valentine, Monica.Valentine@kysu.edu
}

ABSTRACT: The year, 2020, was a wakeup call to corporate America to make unprecedented progress on diversity and inclusion, with the Covid-19 crisis exposing astronomical racial health disparities, and the murder of George Floyd, prompting global protests against racism. The reckoning over race in the U.S. prompted a growing number of leaders to adopt a moral case for communicating a stronger commitment to diversity, but stakeholders are demanding to see real change.

The purpose of this study is to outline the actions that CEOs are taking to communicate about diversity commitment and accountability as defined by the literature, among tech organizations, making the Diversity Inc. 2021 Top 50 Companies for Diversity list. A qualitative content analysis of CEO diversity statements publicly published by four tech companies cited for 'diversity,' identifies leadership diversity actions as building trust, actively working against discrimination and subordination, embracing a wide range of styles and voice, and making cultural differences a resource for learning. These CEO statements were coded for moral legitimacy or the lack thereof. The author found symbolic evidence of moral legitimacy, four leadership perspectives on behavioral change and cultural shift, as well as, similarities and differences in communication practices. These findings will help practitioners craft diversity statements that offer substantive expressions of inclusive actions.

KEYWORDS: Diversity commitment, Accountability, Leadership diversity, Communication practices

\section{ARTICLE INFORMATION}

Author(s): Dr. Monica Valentine

Received: 30 Aug, 2021; Accepted: 05 Oct, 2021; Published: 30 Oct, 2021; e-ISSN: 2347-4696;

Paper Id: BMN-IJBMR-2021-68;

Citation: doi.org/10.37391/IJBMR.090403

Webpage-link:

https://ijbmr.forexjournal.co.in/archive/volume-9/ijbmr-090403.html

\section{INTRODUCTION}

When the coronavirus (Covid-19) pandemic manifested in March 2020, rapidly causing alarming rates of hospitalizations and deaths across the United States, government mandated shelter-in-place orders were issued to shut down, all nonessential businesses, travel and gatherings, changing the way the nation conducts business, possibly forever. The global health crisis forced many customer-oriented companies to quickly move, their entire operations online, utilizing new technologies to integrate customer data analytics in their mobile apps and websites to provide some form of business as usual during such uncertain times [1]. But, there is nothing usual about the challenges that COVID-19 imposes on the wellbeing of employees of color. The social determinants of health for diverse employees have indeed been unprecedented, as the pandemic continues to reveal disparate impact on workplace psychological safety, belonging, work-life balance, and concerns about employment and promotion opportunities - this is especially true for Black identified employees [2].

Adding to the uncertainty of the pandemic, the U.S. entered another recession, leaving millions unemployed [3]. Moreover, racial tensions driven by televised race-based police brutality including the pivotal murder of George Floyd, while in the

custody of Minneapolis police on May 25, 2020. To address the double pandemic of both the Covid-19 crisis and racial discrimination towards Black people, a growing number of CEOs of U.S. based organizations are sharing their personal views about diversity, inclusion, and equity on their corporate websites and social media pages. As organizations are disproportionately, led by white male-identified CEOs, this increase in visible ally-ship, from those privileged to lead, is unique and compelling. According to the diversity management literature, visible leadership related to corporate diversity statements "play(s) a key part in socially constructing how diversity should be regarded in the company by minority and majority groups, as well as, indicating corporate values to external stakeholders" [4]. That a growing number of CEOs and senior leadership are the voices and platforms of organizations, to express a visible commitment to and accountability for diversity awareness, representation metrics, and diversity management practices, suggests movement in the shared work of racial equity and social justice [5].

Notably, the Diversity Inc. 2021 Top 50 Companies for Diversity's list lacks major tech companies, highlighting a longstanding criticism of the tech sector's lack of minority representation and authenticity when it comes to facilitating psychologically safe workplaces that value diversity, equity and inclusion across identities [6-8]. Given the necessity to survive and continue providing services and products during Covid-19, many traditionally in-office functions are moving online and there is a heightened focus for companies to use metrics to measure progress in hiring, promoting, and retaining minority employees. Leaders of tech companies, in particular, have an unprecedented opportunity to rise to the occasion and identify with their minority employees, what their corporate social values are, and move forward building more equitable, and inclusive workplaces [9-11]. Diversity 
statements are one platform that organizations use to attract diverse talent and customers [9, 12], but little structured information is known about how leaders of tech companies articulate a shared racial justice vision with their stakeholders through corporate diversity statements. To the knowledge of the researcher, there has been no prior research studying diversity statements of U.S. based tech companies, in terms of leadership commitment and accountability towards behavioral change and cultural shifts of organizations. Thus, the purpose of this study is to outline the actions that CEOs are taking to communicate diversity commitment and accountability as defined by the literature, and to examine which behavioral changes are key to fostering inclusion and creating cultural shifts, among tech organizations, making the Diversity Inc. 2021 Top 50 Companies for Diversity list.

\section{BACKGROUND}

\subsection{Symbolism is not Enough}

The way companies conduct business continues to evolve in response to normative stakeholder pressures and the unique challenges created by the pandemic, as well as, the existing racial tension in the U.S. On the one hand, organizational strategies must align with emerging social values in order to remain competitive $[11,13]$. On the other hand, the coronavirus, police brutality, and systemic racism have caused greater public scrutiny of organizations, and the perceived lack of effective leadership, is causing an uptick in stakeholder concerns about diversity practices. As external factors and employee concerns continue to exert extreme pressure on organizations to conform to social expectations and environmental standards, business leaders must decide how to respond [11, 14]. The literature argues that coercive and normative pressures from both internal constituencies and external forces cause organizations to adopt environmentally protective policies to demonstrate their commitment to diversity [15]. As such, CEOs are influenced by their environment "to do the right thing," driving substantive corporate commitment to diversity practices, reflecting their dedication to an inclusive culture [9, 11, 16, 17]. However, organizations that choose to respond to external pressures (such as Covid-19 and social injustice) are more likely to simply create the appearance of symbolic commitment to diversity and invest more time, superficially managing diversity practices and their corporate image $[9,15,18,19]$.

\subsection{Exposing the Lack of Black Talent in the Tech Industry}

Diversity is the perceived variation of social and cultural identities among employees, where differences and similarities are valued [20-22]. Companies adopting a business case for diversity align their actions and beliefs with business needs from a metrics perspective, in an effort to remain compliant with equal employment opportunity, to access new talent and markets, increase profitability, and enhance corporate reputation and image [23, 24]. Diversity becomes inclusive when leaders enforce the practice of valuing respect and acceptance of others. Loyalty and trustworthiness are emphasized ensuring, a supportive environment for each person to achieve their full potential [25].

Although there are many reasons why companies should invest in diversity, new research in the tech sector reveals that there is a lack of transparency about workforce demographics, especially when it comes to bias against Blacks in employment decision making $[26,27]$. Therefore, decades of research supporting the business case for racial diversity [23, 28] has been, recently questioned, in terms of improving financial outcomes [28, 29]. Research finds that increasing racial diversity in the workplace does not guarantee benefits alone. According to Ely \& Thomas [30], some organizations refuse "to reconfigure power relations" with their diverse employees, making it difficult to make them feel genuinely valued and respected (p. 118).

This may explain why the tech industry has endured many systemic challenges, including racial bias, unfair treatment, stereotyping, bullying, and unwanted sexual advances that impede the full participation of minorities in the STEM field. In 2014, the Equal Employment Opportunity Commission used EEO-1 data to identify the following demographic concerns:

- The tech sector employed more whites (68.5 percent) and Asian Americans (14 percent) than Blacks ( 7.4 percent); Of those employed at tech firms in Silicon Valley, less than 1 percent were Black

- Whites made up the largest share of professionals (68.03 percent), Asian Americans the second largest share (19.5 percent), and Blacks with the least (5.27 percent)

- The majority of Executives tech Executives nationwide were white (83.3 percent); 10.5 percent were Asian American, and Blacks were represented at the lowest rate in Executive roles (2 percent); When the Executive and Manager roles are combined, Blacks at tech firms in Silicon Valley made up less an 1 percent

- Of those in tech Executive roles, about 80 percent were men and 20 percent were women.

It is clear that the tech workforce lacks racial diversity. Tech remains a white and male dominated industry, especially in Silicon Valley, where tech companies are investing more in diversity today than ever before $[31,32]$. Yet, the demographics of the tech industry as a whole tells a much different story, of big tech companies that employ very few Black employees in technical and executive roles, and those that are allowed in, are confronted with racial bias and microaggression [33].

\subsection{Leaders as Opportunities during a Crisis}

A crisis, such as the Covid-19 pandemic, in addition to perceived and observed injustice against Blacks, can disrupt an organization and destabilize its employees as they struggle to adapt to the new reality of work [34]. As these disruptions continue, leaders must be able to manage the various cultures, 
preferences, and expectations of a diverse workforce and society $[35,36]$. Addressing the state of the nation's social, economic, and health systems has become a corporate social responsibility that calls into question the purpose of the role business should play in society [37]. The lack of diversity, especially of the Black population, in corporate America has weakened public trust and has created a demand for businesses leaders to share the same perspective of their stakeholders [38, 39]. The responsible leadership literature suggests that during crises, organizations are perceived positively by minorities under leaders who share a joint purpose, morals, and ethics with their employees [40, 41]; communicates with transparency and optimism [42]; and prioritizes employees' emotional stability [43].

\subsection{Inclusive Leaders and Organizations}

According to the diversity management literature, leaders should avoid over emphasis on financial performance, and focus more on being genuinely concerned about empowering their people to have a voice in defining the role that diversity plays in employment practices, organizational culture, and business strategies [4, 9, 44, 45] Recent research, however, confirms that a number of organizations continue to refute business case arguments for diversity [46, 47]. Many companies approach diversity from a performance lens, but it is important to acknowledge that, "all demonstrate good intentions; and none of the claims is actually supported by robust research findings" [30]. In fact, studies on diversity management explain that it is difficult to quantify long-term progress of diversity efforts, such as, managing values and cognitive processes of employees who may share the same physical or cultural traits, yet differ in terms of other dimensions of diversity [48-50].

Imperative to this study is the idea that as corporate America continues to become more diverse, business leaders will have a higher level of obligation and accountability to society, to achieve increased outcomes and results. As such, recent research encourages diversity supporting organizations to present a more inclusive image in external facing disclosures, such as diversity statements, to gain trust and appeal for legitimacy [9]. Some organizations choose to conform to the diversity structures, procedures and practices of competitors within the industry who are already, perceived as being legitimate, while others are more concerned with informing stakeholders about diversity management as a means to convey socially legitimate goals, practices and outcomes to diverse stakeholders [9].

Still there remains, a growing demand for companies to be more accountable, and trustworthy in their diversity practices and for corporate diversity statements to reflect more transparency and credibility about actual diversity practices [51]. To this end, authentic leaders who appeal for moral legitimacy in their diversity statements must aim to build trust through 'doing the right thing' and focusing on transparent and ethical relationships with employees [9]. Such leaders must articulate how they are addressing current and anticipated problems that may arise from differences, in order to reduce agency costs of employee behavior through diversity initiatives, such as equality policies, diversity and inclusion training, as well as, diversity councils and boards to attract and retain diverse stakeholders and allies [9]. With leadership commitment to diversity, organizations appealing for moral legitimacy can expect to learn from differences, while influencing behavioral changes and creating cultural shifts [30].

\subsection{Method and Sample Construction}

A qualitative content analysis, was chosen for this study, to understand, subtle, implied, and connotative meaning that a quantitative study cannot provide [52]. A sample was drawn, from the Diversity Inc. Top 50 Companies for Diversity list, because Diversity Inc. is well known for its diversity metricsdriven evaluation of U.S. corporations, in which companies have been voluntarily judged based on their diversity practices since 2001. Four organizations were selected from this list, because they are the only technology companies that made the list: Comcast NBC Universal (ranked 6 by Diversity Inc.), Medtronic (ranked 11), Northrop Grumman (ranked 21), and Raytheon Technologies (ranked 45). These four organizations are listed in Exhibit 1, along with their diversity management rankings and leadership names/titles, as provided on the Diversity Inc. webpage. These organizations are representative of major U.S. tech corporations, as they are governed by the same employment laws, and are positively rated, by the majority of their employees.

Diversity Inc. claims to conduct the "most extensive, datadriven analysis gauging detailed demographics based on race/ethnicity and gender at some of the largest U.S. employers, all in an effort to benchmark organizations' programs, practices, policies, and outcomes to hire, retain, develop and promote women, people of color, people with disabilities, LGBTQ and veteran employees." The survey's methodology has evolved since 2001. During 2021, over 1,800 companies participated in the free Diversity Inc. study through a multiple-choice survey. With more than 200 questions, the survey is organized in six key areas: Human Capital Diversity Metrics, Leadership Accountability, Talent Programs, Workplace Practices, Supplier Diversity, and Philanthropy. Respondents provide information on workforce demographics, such as race/ethnicity of different levels of management, retention rates by gender for minority managers, as well as, the volume of loans and other financial assistance offered to minority and women owned suppliers. To be selected for the list, companies must score above average in all six areas.

This study examines these tech companies' CEO statements in response to the racial injustice occurring in the U.S. after George Floyd's murder on March 25, 2020. These CEO statements are publicly available on each of the corporate websites. The researcher conducted a qualitative content analysis of the published CEO statements of each of the technology companies. Following Singh \& Point [9], the researcher chose a theory-driven approach for category development to ensure the validity of the applied coding scheme. The researcher created a collection of diversity 
management practices, behavioral changes, and cultural shifts, based on existing frameworks. The procedure is described, in detail, in the following section.

\subsection{Coding Scheme}

The primary objective of this study is to assess the actions that CEOs are taking to communicate about diversity commitment and accountability as defined by the literature. The secondary purpose of this study to determine whether the tech leaders communicate an interest in learning from racial differences to inspire behavioral change that fosters inclusion and cultural shifts, within their organization. In an effort to uniformly, capture leadership commitment, learning from racial differences, behavioral change, and cultural shift, information a search on the landing page of each of the four companies was employed using search words from each category listed in Table 1. Using Krippendorff's [53] coding guidelines, the researcher, a trained coder, read all of the CEO statements and developed a coding scheme. As a single coder, the researcher developed a codebook based on theoretical concepts from the literature and engaged in manual coding to define themes and to determine frequency of occurrence. In order to be considered as a subtheme, it had to be mentioned at least once in the sample statement. After identifying the diversity management practices mentioned in the websites, the information was sorted into common themes by following Table 1, which in turn led to the development of the selected categories.

\begin{tabular}{|c|c|c|}
\hline $\begin{array}{l}2021 \text { Ranking } \\
\text { and Company }\end{array}$ & $\begin{array}{l}\text { Diversity } \\
\text { Management } \\
\text { Ranking }\end{array}$ & $\begin{array}{l}\text { Leadership } \\
\text { Name/Title }\end{array}$ \\
\hline $\begin{array}{l}\text { (6) Comcast } \\
\text { NBC Universal }\end{array}$ & $\begin{array}{l}\text { (16) Top Companies } \\
\text { for People with } \\
\text { Disabilities } \\
\text { (5) Top Companies } \\
\text { for Supplier } \\
\text { Diversity } \\
\text { (22) Top Companies } \\
\text { for LGBTQ } \\
\text { (22) Top Companies } \\
\text { for Executive } \\
\text { Diversity Councils } \\
\text { (1) Top Companies } \\
\text { for Talent } \\
\text { Acquisition for } \\
\text { Women of Color } \\
\text { (9) Top Companies } \\
\text { for Veterans } \\
\text { (13) Top Companies } \\
\text { for Latino Executives } \\
\text { (6) Top Companies } \\
\text { for Black Executives } \\
\text { (6) Top Companies } \\
\text { for Native } \\
\text { American/Pacific } \\
\text { Islander }\end{array}$ & $\begin{array}{l}\text { Brian L. Roberts, } \\
\text { Chairman and } \\
\text { CEO } \\
\text { Dalila Wilson- } \\
\text { Scott, Executive } \\
\text { Vice President } \\
\text { and Chief } \\
\text { Diversity Officer }\end{array}$ \\
\hline (11) Medtronic & $\begin{array}{l}\text { (3) Top Companies } \\
\text { for Supplier } \\
\text { Diversity }\end{array}$ & $\begin{array}{l}\text { Geoff Martha, } \\
\text { Chairman and } \\
\text { CEO }\end{array}$ \\
\hline
\end{tabular}

\begin{tabular}{|c|c|c|}
\hline & & $\begin{array}{l}\text { Dr. Sally Saba, } \\
\text { Chief Inclusion } \\
\text { and Diversity } \\
\text { Officer }\end{array}$ \\
\hline $\begin{array}{l}\text { (21) Northrop } \\
\text { Grumman }\end{array}$ & $\begin{array}{l}\text { (10) Top Companies } \\
\text { for People with } \\
\text { Disabilities } \\
\text { (21) Top Companies } \\
\text { for LGBTQ } \\
\text { (4) Top Companies } \\
\text { for Employee } \\
\text { Resource Groups } \\
\text { (12) Top Companies } \\
\text { for Mentoring } \\
\text { (17) Top Companies } \\
\text { for Executive } \\
\text { Diversity Councils } \\
\text { (2) Top Companies } \\
\text { for Native } \\
\text { American/Pacific } \\
\text { Islanders }\end{array}$ & $\begin{array}{l}\text { Kathy J. Warden, } \\
\text { Chair, CEO and } \\
\text { President } \\
\text { Sandra J. Evers- } \\
\text { Manly, Vice } \\
\text { President, Global } \\
\text { Corporate } \\
\text { Responsibility }\end{array}$ \\
\hline $\begin{array}{l}\text { (45) Raytheon } \\
\text { Technologies }\end{array}$ & $\begin{array}{l}\text { (18) Top Companies } \\
\text { for Executive } \\
\text { Diversity Councils }\end{array}$ & $\begin{array}{l}\text { Gregory J. Hayes, } \\
\text { CEO } \\
\text { Marie R. Sylla- } \\
\text { Dixon, Chief } \\
\text { Diversity Officer }\end{array}$ \\
\hline
\end{tabular}

Table 1: Diversity management and leadership.

\subsection{Coding Procedure}

Manual coding supplemented interrater reliability testing. Calculations were computed both by hand and by using the software, ReCal2 to calculate percentage agreement [54]. The coding procedure was performed by one coder to ensure consistency within the analysis. As the information coded was publicly available on corporate websites, with a predefined and explicit coding scheme, the coding procedure did not require subjective interpretation of the coder's interpretative scheme as it would be the case with latent content. To address single coder bias and avoid coder fatigue, open coding, was used during the initial coding process to break up text into smaller chunks and enough time was allotted to complete the task, ensuring that the researcher could be as objective as possible and gain as many relevant perspectives as possible. This approach has limitations to the coding process. Therefore, future studies could use alternative coding strategies that use multiple coders to add rigor to the process [55].

Prior to the actual coding of the statements, the coder conducted a test coding session, where all assigned and rejected codes were assessed. In case of doubt, codes were marked and double-checked by the researcher. Not all of the categories identified were used in this study's analysis. The codebook for this study was updated and revised, so that clear and operational definitions could produce categories that do not overlap. Each company was coded for the presence or absence of diversity management practices relating to the diversity leadership practices identified in Table 1. It should 
be understood that tallies within each category represent the frequency of the observed item and is not an assessment of quality for each instance. The researcher focuses on the CEO statements on racial justice in this article because it is of greatest value in her efforts to generate theory.

\section{DATA ANALYSIS}

\subsection{Leadership Perspectives on Diversity}

The researcher identified themes that might explain similarities and differences within and across the organization's experiences of diversity, in particular, how leaders communicated a diversity mission towards changing behaviors and the culture of their organization to be more inclusive after a crisis. All four diversity leadership practices from the literature were found in the CEO statements [30]. However, the researcher identified an additional four leadership perspectives on behavioral change and cultural shift that appear to have implications for how well leaders communicate diversity commitment. This became the working hypothesis that framed and guided the remainder of the data analysis.

These four different diversity perspectives appeared to have different implications for how well the CEO statements addressed the Covid-19 pandemic and racial injustice. Therefore, it is difficult to determine how likely potential unstable psychological safety could impact employee ability to realize the benefits of the learning-and-effectiveness paradigm, in particular, their leader's ability to build trust, actively work against discrimination and subordination, embrace a wide range of styles and voice, and make differences a resource for learning. However, what this study addresses is that each leader provides a rationale for why employees should engage in behavioral change and increase cultural diversity.

\subsection{What then makes Organizations and} Leaders, Inclusive?

Part of the reason why organizations do not see the benefit of diversity is because they continue to treat differences as problems to be fixed rather than as opportunities, for a competitive advantage [56]. At the same time, research indicates that the perception of employees toward inclusion at an organization depends on, whether they are fully engaged, feel safe, and valued, despite having different social identities $[57,58]$. Prior research on diversity management and personorganization fit suggests that organizations communicate about their diversity practices, promote a workplace free of discrimination and are more attractive to diverse talent [59]. This remains true today [30]. The literature also agrees that organizations are typically regarded as diversity 'employers of choice,' when their job candidates and employees believe that their values are aligned with what they perceive the organization's norms and values about diversity to be $[60,61]$. Perceived organizational inclusion increases innovation, creativity, job performance and productivity, employee retention, and satisfaction when shared understanding of inclusion exists and leaders make members of diverse teams feel like they belong and that their uniqueness and contributions are valued $[8,62]$ (Table 2).

Diversity Leadership
Communication Practices
Build Trust
Effective leaders should
create connection through
pain and facilitate
psychological safety
*Supporting Black
employees' personal lives
matters

Actively work against

Discrimination \&

Subordination

Effective leaders should

acknowledge systemic systems

of privilege and use personal

examples to inspire

meaningful sustained change

towards inclusion *Mitigating acts of bias and privilege in hiring and promotion to be more inclusive of Black employees.

\section{Embrace wide range of} Styles \& Voices

Effective leaders understand that organizational norms might implicitly discourage certain behavioral styles or silence Black voices

*Encouraging meaningful conversations to influence the implementation of practices, policies and programs that support spaces where Black employees feel they can speak honestly without fear.

\section{Make Cultural Differences}

resource for Learning

Effective leaders have cultural intelligence and confidence to lead cross-cultural teams,
Example Phrases from

CEO statements

"I'll lend my contributions of time and resources to continue to try and make progress on the issues of community and race" "It has been heartbreaking to witness these painful events unfold, including the murder of George Floyd" "equity and inclusion have been deeply rooted values since our founding. And they remain defining truths of who we are and what we do"

"I won't tolerate itwhether it be the act that killed Mr. Floyd or the acts of those burning this city" "We also have a distinct opportunity to improve the diversity of talent throughout our company at every level" "We recently expanded upon our decadelong efforts to close the digital equity gap with a $\$ 1$ billion commitment to...ensure communities of color have the skills and tools necessary to succeed" "Collectively, we've helped to support small businesses owned by people of color"

"we've helped to... amplify

diverse voices to inspire and inform; and provide resources to empower underserved communities" "let the tragedy of Mr. Floyd's death remind us that there is no room for abuse of power and that we have to seek to understand experiences and perspectives that are different from our own"

"I will also continue to provide all of my support to our Networks and ERGs...to help drive change inside and outside of our walls" 
empowering employees to challenge the status quo and

build upon each other's ideas.

*Building a culture where

behaviors reflect awareness of privilege, bias, psychological safety, valuing diversity and inclusion, and being committed to learning from others.

\begin{abstract}
"I'm encouraged by the many ways we've seen our employees support each other and come together with our partners to make our company and communities stronger and more reflective of the world we want it to be" "Since we made our commitment to accelerate the fight against injustice and inequality, I'm proud of how the entire organization has learned to do more - listening, learning, and creating new programs that are having a meaningful impact beyond our walls"
\end{abstract}

Table 2: Phrases used for coding [30].

Despite increased investments in corporate diversity and inclusion in recent years, few organizations truly understand the needs of their stakeholders, and why addressing these needs is critical to the corporate diversity mission [63]. In 1996, Thomas \& Ely published a Harvard Business Review article, "Making Differences Matter: A New Paradigm for Managing Diversity," which argues for organizations to engage their employees and leaders in shared-learning of cultural competencies, allow differences to enhance work, and measure progress by the extent that the ideas and perspectives of underrepresented groups change the culture of the organization. More specifically, the authors approach diversity management as a learning-and-effectiveness paradigm, which is more than just being aware of differences; it is where differences are embraced, discussed, disputed, and conflict is resolved [23].
Thomas and Ely revisited this learning-and-effectiveness paradigm in 2020, extending the learning-and-effectiveness approach to focus on four actions leaders should take to "create a psychologically safe workplace, combat systems of discrimination and subordination, embrace the styles of employees from different identity groups, and make cultural differences a resource for learning and improving organizational effectiveness" (p. 117). Thomas \& Ely [30] provide four steps to facilitate the shift to behavioral change and cultural shifts (see Table 1).

\section{\%. FINDINGS: LEARNING-AND- EFFECTIVENESS PARADIGM}

\subsection{Build Trust}

In the past, few leaders might have considered publically addressing social issues. Today, it is critical for leaders to know how to make sense of and authentically communicate their position on racial injustice, in order to build trust with Black employees and their allies, and meet the expectation many have for organizations to be responsible for driving moral and more equitable outcomes for society. In the midst of racial tension, leaders across the nation recognize the fact that employees are only as engaged in their work as the safety they feel within the organization's culture. In other words, because a positive employee experience depends upon how well the organization can create a culture that is appealing to individuals [64], leaders must take time to investigate the ways that distrust may be governing organizational behavior, metrics, and policies. Following George Floyd's murder, for example, diversity-supporting leaders established psychological safety when they found the courage to publicly empathize on behalf of their companies to their Black employees "who might already have been feeling marginalized or undervalued at work" [30] (Table 3).

\begin{tabular}{|l|l|l|l|l|}
\hline Perspectives & $\begin{array}{l}\text { Make Cultural } \\
\text { Differences Resource } \\
\text { for Learning }\end{array}$ & $\begin{array}{l}\text { Embrace Wide Range of } \\
\text { Styles and Voices }\end{array}$ & $\begin{array}{l}\text { Actively Work Against } \\
\text { Discrimination and } \\
\text { Subordination }\end{array}$ & Build Trust \\
\hline $\begin{array}{l}\text { Rationale for } \\
\text { inclusion }\end{array}$ & $\begin{array}{l}\text { To leverage shared } \\
\text { cultural knowledge and } \\
\text { experiences to inform } \\
\text { and enhance work }\end{array}$ & $\begin{array}{l}\text { To demonstrate } \\
\text { understanding that } \\
\text { organizational norms } \\
\text { might implicitly } \\
\text { discourage behavioral } \\
\text { styles or silence voices of } \\
\text { Black employees }\end{array}$ & $\begin{array}{l}\text { To dismantle systems of } \\
\text { discrimination and } \\
\text { subordination that inhibit } \\
\text { Black employees }\end{array}$ & $\begin{array}{l}\text { To create } \\
\text { psychologically safe } \\
\text { spaces where Black } \\
\text { people feel safe to } \\
\text { work and express } \\
\text { themselves freely }\end{array}$ \\
\hline $\begin{array}{l}\text { Leadership } \\
\text { commitment level }\end{array}$ & $\begin{array}{l}\text { High: leader listens to a } \\
\text { variety of ideas, learns } \\
\text { from differences, and } \\
\text { risks leading change; } \\
\text { leader has created trust, } \\
\text { begun to dismantle } \\
\text { discrimination, } \\
\text { subordination, and } \\
\text { embraces broad range of } \\
\text { styles and voices }\end{array}$ & $\begin{array}{l}\text { Moderate: leader may } \\
\text { unintentionally assimilate } \\
\text { to dominant white culture } \\
\text { during a crisis; leader } \\
\text { begins to listen to others }\end{array}$ & $\begin{array}{l}\text { Average: a starting point } \\
\text { for leaders to produce } \\
\text { systemic change and } \\
\text { empower Black } \\
\text { employees; leader learns } \\
\text { about how systems of } \\
\text { privilege are oppressive } \\
\text { and uses this knowledge } \\
\text { to articulate a shared } \\
\text { organizational mission for } \\
\text { learning and systemic }\end{array}$ & $\begin{array}{l}\text { Low: a basis for } \\
\text { leaders to set the tone } \\
\text { for difficult } \\
\text { conversations and } \\
\text { create spaces where } \\
\text { Black employees feel } \\
\text { they can speak } \\
\text { honestly without fear }\end{array}$ \\
\end{tabular}




\begin{tabular}{|c|c|c|c|c|}
\hline & & & change & \\
\hline $\begin{array}{l}\text { Connection } \\
\text { between behavior } \\
\text { and cultural } \\
\text { diversity to } \\
\text { improve work }\end{array}$ & $\begin{array}{l}\text { Direct: leader attempts } \\
\text { to motivate and guide } \\
\text { change with reflection } \\
\text { and consciousness- } \\
\text { raising, } \\
\text { experimentation, and } \\
\text { action; leader talks } \\
\text { about actions/evidence } \\
\text { organization has taken } \\
\text { to promote equality } \\
\text { throughout the } \\
\text { organization and } \\
\text { intolerance of } \\
\text { discrimination and } \\
\text { subordination }\end{array}$ & $\begin{array}{l}\text { Indirect: leader tries to } \\
\text { understand how } \\
\text { organizational norms } \\
\text { might be limiting work; } \\
\text { leader attempts to } \\
\text { motivate and guide } \\
\text { change with a cycle of } \\
\text { reflection and } \\
\text { consciousness-raising and } \\
\text { experimentation }\end{array}$ & $\begin{array}{l}\text { Indirect: leader attempts } \\
\text { to motivate and guide } \\
\text { change with reflection and } \\
\text { consciousness-raising }\end{array}$ & $\begin{array}{l}\text { Limited: leader } \\
\text { recognizes } \\
\text { organizational norms } \\
\text { exist against } \\
\text { connection }\end{array}$ \\
\hline $\begin{array}{l}\text { Indicators of } \\
\text { progress }\end{array}$ & $\begin{array}{l}\text { Communicates learning } \\
\text { about differences leads } \\
\text { to Behavior \& Culture } \\
\text { Change: Leader uses } \\
\text { substantive statements } \\
\text { to acknowledge that } \\
\text { inequality is bad for } \\
\text { both business and } \\
\text { society; leader supports } \\
\text { all employees as full } \\
\text { participants in the } \\
\text { organization; leader } \\
\text { engages in shifting the } \\
\text { conversation from the } \\
\text { business case to a moral } \\
\text { position; leader insists } \\
\text { everyone actively listens } \\
\text { to and learns from one } \\
\text { another to enhance self- } \\
\text { awareness and shape the } \\
\text { culture }\end{array}$ & $\begin{array}{l}\text { Communicates Inclusion } \\
\text { as being curious about } \\
\text { differences: Leader uses } \\
\text { symbolic statements to } \\
\text { acknowledge that } \\
\text { organizational norms } \\
\text { might implicitly } \\
\text { discourage Black } \\
\text { employees; leaders also } \\
\text { are aware that stereotypes } \\
\text { exist within the } \\
\text { organization }\end{array}$ & $\begin{array}{l}\text { Communicates Inclusion } \\
\text { as diversity programs, } \\
\text { groups, trainings and } \\
\text { policies: Leader uses } \\
\text { symbolic statements to } \\
\text { deflect meaningful } \\
\text { change; organizational } \\
\text { norms limit perspectives } \\
\text { and ideas of Black } \\
\text { employees from } \\
\text { influencing work }\end{array}$ & $\begin{array}{l}\text { Communicates } \\
\text { Diversity Awareness: } \\
\text { Leader uses symbolic } \\
\text { statements to show } \\
\text { willingness to listen, } \\
\text { speak, act, and receive } \\
\text { feedback on racial } \\
\text { justice }\end{array}$ \\
\hline
\end{tabular}

Table 3: Summary of behavioral change and cultural shift perspectives.

Many white leaders stepped out of their comfort zones, finding it much easier to respond to the uncertainty and fear of Covid19 , than racial injustice, as they struggled to address "the deep grief, rage, and despair felt by many of their employeesespecially their Black employees. And Black leaders, many with firsthand experience of police mistreatment and other forms of racial oppression, faced the challenge of managing their own strong emotions and speaking their truth without appearing biased against whites" [30]. Some leaders took it a step further and acknowledged that their Black employees may need time for self-care to heal from direct and indirect trauma [30]. The analysis for the current study did not find any reference from the four tech company CEO statements that conveyed empathy or support toward the psychological safety of Black employees, in particular. However, the statement from Medtronic's CEO, Geoff Martha was the closet:

The news and video of the apprehension and death of George Floyd and the ensuring unrest in Minneapolis has rattled me, and I know it has rattled you...I've come to learn that some of our employees knew Mr. Floyd, and they are mourning his loss. My sympathies to you and to Mr. Floyd's family.

All organizations have an interest to improve their diversity image and maintain moral legitimacy when it comes to leveraging racial diversity to access new markets and to preserving relationships with existing minority stakeholders and their allies $[9,60]$. This approach to diversity management claims that organizations have a moral responsibility to society, and individuals, to hold leaders and employees accountable for their actions towards people who do not look like them [20]. The language used by tech company leaders in this study suggests that they encourage both personal responsibility and collective accountability for making diversity, equity and inclusion a priority. A CEO who handles this well is Northrup Grumman's Kathy J. Warden:

Our annual Sustainability Report provided transparency into the progress and actions we've taken across our environment, social and governance (ESG) priorities. We highlight our 
achievements in 2020, including the actions we took in response to the Covid-19 pandemic and calls for social justice and unity. I am so proud of how we supported our employees, families, communities, suppliers and customers, and created new ways to operate to fulfill our collective mission...Last year, we restated and reaffirmed those Values, clearly defining what we should expect from our company and from one another.

According to the literature, progressive leaders build trust and drive cultural change by taking time for self-reflection and personal change of their leadership style, so that they can better understand their own stereotypes and implicit biases, before they begin to learn the perspectives of minority stakeholders $[8,65]$. However, one CEO statement assessed in this study sent a rather confusing message to employees in Minnesota by taking light of the abuse of authority by police, or what is also commonly referred to as police brutality:

The news and video of the apprehension and death of George Floyd and the ensuing unrest in Minneapolis has rattled me... This isn't how we treat people...I am hopeful that justice will be served for Mr. Floyd... And like you, I also understand that there are men and women in police uniforms who do their jobs the right way, and we thank them for it.

This same CEO statement focused more on personal responsibility, than on collective accountability:

I am reaching out to our partners in this city, and I'll lend my contributions of time and resources to continue to try and make progress on the issues of community and race. I will also continue to provide all of my support to...help drive change.

The researcher found a lack of evidence in the CEO statements examined in this study that called for an elimination of biases and racism in the workplace. The expectation was to find language that would support the idea that each leader understood that now is not the time to prioritize the needs of the dominant group, whether that is to make white employees feel comfortable or to minimize the impact of discrimination and inequality within the walls of their organization. The focus should have been on describing psychologically safe spaces for Black employees through substantive statements that focused on holding everyone accountable for valuing the lives of Blacks in society and representation of Black employees in the workplace. In fact, there was only symbolic discourse from the tech leaders urging employees to hold each other accountable:

"We have to respond clearly that racism, discrimination and hatred will not be tolerated."

“...the Black Lives Matter movement and too many injustices continue to show us that there is much work to be done to create real and lasting change."

"Creating a more equitable sustainable world requires more than just a commitment - it demands taking responsibility and action to create lasting change."
None of the statements reflect the leaders holding themselves responsible for talking about personal bias and racism. The goal should be for CEO statements on racial justice to come across with empathy and humility, allowing for a strong moral compass, which happens to align with the right thing to do, guiding employees to express a desire of understanding and learning from diverse perspectives [30]. Studies find that leaders gain trust, because they create "opportunities to discuss, debate, refine and build on the ideas of their employees" [30]. Gregory J. Hayes, CEO of Raytheon Technologies was especially evident in expressing trust. His statement acknowledged that it is important for employees to have difficult conversations without fear:

\section{Colleagues-}

Over the weekend, we witnessed protest and unrest in many of our cities, and I want to address it directly. The death of George Floyd was the result of a reprehensible act... We must take this moment to embrace the fundamental values that unite use...As we continue to build a culture of inclusion that supports diversity in its broadest sense...Complex issues raise difficult questions and conversations. Mutual trust and respect will guide the path forward as we build a more diverse and inclusive global community.

The literature emphasizes that to build trust, leaders must be transparent and willing to admit that they do not have all of the answers and may make mistakes, but are willing to have an open mind to learn from others to resolve conflict and challenges [30, 65]. All of the CEO statements assessed, demonstrated some level of trust. Otherwise, organizations that do nothing about racial discrimination are seen as being complicit. As such, an organization's moral legitimacy is at stake, if it is not actively working against discrimination and subordination [30].

\subsection{Actively, Work against Discrimination and Subordination}

Leaders new to managing diversity take a fairness approach toward diversifying the organization in representation only, assuming that everyone is the same, and implementing programs that ensure fair treatment and equal opportunity [23]. Thomas \& Ely [23] agree that equal opportunity for all is good, but organizations need to "internalize differences among employees so that it learns and grows because of them" (p. 7). They go on to identify eight preconditions that guide leaders to making a cultural shift:

1. Leadership must understand that a diverse workforce embodies different perspectives and approaches to work, and leaders must truly value variety of opinion and insight;

2. Leadership must recognize learning opportunities and the challenges that the expression of different perspectives presents for an organization;

3. The organizational culture must create an expectation of high standards of performance for everyone; 
4. The organizational culture must stimulate personal development;

\section{The organizational culture must encourage openness;}

6. The culture must make workers feel valued;

7. The organization must have a well-articulated and widely understood mission; and

8. The organization must have a relatively egalitarian, nonbureaucratic structure [23].

While organizations do not have to master all eight preconditions, Thomas \& Ely [23] observed that organizations tend to meet at least four preconditions prior to beginning a shift toward learning from diversity. Therefore, it is important that leaders do more than just promote diversity awareness; they must also, learn from differences and address the real psychological safety issues within the organizational culture $[22,30]$. Most organizations attempt to do this by implementing a number of diversity programs, such as affinity groups, mentoring programs, work-life balance initiatives, and unconscious bias trainings, but the research finds that these efforts "fail to produce meaningful, sustained change-and sometimes even backfire" [30]. Organizations need a leader who can facilitate "open and explicit discussion of what identity-group differences really mean and how they can be used as sources of individual and organizational effectiveness" [23]. Only one of the four tech CEOs did not mention their organization's diversity programs, groups, trainings, or initiatives. Geoff Martha, detailed his support for having open discussion with others who are different from him to move Medtronic forward:

Please know that I am reaching out to our partners in this city, and I'll lend my contributions of time and resources to continue to try and make progress on issues of community and race. I will also continue to provide all of my support to our Networks and ERGs so that Medtronic continues to have a mechanism to help drive change inside and outside of our walls.

Brian L. Roberts, Chairman and CEO of Comcast NBC Universal also shared how differences are leading to positive impact in his organization:

We made our commitment...to accelerate the fight against injustice and inequality, I'm proud how the entire organization has leaned in to do more-listening, learning, and creating programs that are having a meaningful impact... We (have) a distinct opportunity to improve the diversity of talent throughout our company at every level, including in front of and behind the camera...Ultimately, across all that we do, our mission remains the same - we connect people to what matters most. We use our platforms and resources to help elevate potential and provide everyone with access to the opportunities they need to succeed.
What employees, especially Black employees, need is to feel a sense of belonging and psychological safety, because trust requires safety. The literature claims that employees look for signals of trust and safety to validate their willingness to play by the rules [66-68]. For employees who are looking for what's in it for me? CEO statements that make racial representation transparent in terms of hiring by job level and promotion rate and leadership levels are important. Kathy J. Warden, CEO and President of Northrup Grumman acknowledged an increase in diversity representation as follows:

Our strong culture is founded in ethics, integrity and our enduring commitment to diversity, equity and inclusion. We had a record year of new hires, bringing ever greater diversity, skills and capabilities to our team.

Although none of the CEO statements provided statistics on their organization's demographics or detailed what their organization has done to increase diversity recruitment or promotion, it is important to note that providing such information would be a positive indicator that the organization is aware of and working towards pay equality, acceptable career progression and employee experiences in general for Blacks.

Psychologically unsafe environments are stomping grounds for employees who harbor distrust, suspicion, jealousy and other characteristics of toxic cultures. However, when the social contract is intact, employees feel psychologically safe, and are more likely to be their authentic selves, ask questions, raise concerns, express new ideas, admit mistakes, and talk through challenges [69]. Creating engaging spaces is essential to building high-performing teams, in which all employees exhibit confidence, creativity, and trust, while the organization benefits from reduced turnover and safety incidents [70]. Leaders who are successful in building trust and psychologically safe cultures are skilled in learning from cultural differences and are more likely to encourage diversity of thinking, empowering employees to express their opinions to management about issues affecting them or their colleagues without fear of being embarrassed, rejected, or reprimanded [30]. In other words, leaders who are willing to become uncomfortable with themselves, enough to personally, change are more likely to lead organizational change, dismantling systems of discrimination and subordination, ensuring that everyone has opportunity and a voice [30].

\subsection{Embrace a Wide Range of Styles and Voices}

Perceived psychological safety or the lack thereof, within a diverse workplace impacts, every part of an organization. The Covid-19 pandemic along with racial injustice issues have caused mental health issues to move to the top of the agenda for corporate leaders. Moreover, it is for good reason, because making time to create a sense of belonging in the workplace is worth the investment, especially given that Black employees experience the workplace and life in general, in different ways than their non-Black colleagues. Systemic and structural inequalities of the larger society in which we live influence 
workplace cultures and bureaucracies [71]. To that end, systems of White privilege force Black employees to work in environments where they "likely feel more apprehensive in freely expressing themselves, which further illustrates the importance of psychological safety in such settings" [72]. Simply put, white privilege creates a dominant cultural space of unearned advantages, benefits and rights given to white people where their racial identity influences both social and workplace norms in such a way that keeps minorities marginalized. This is why understanding "how organizational norms might implicitly discourage certain behavioral styles or silence certain voice(s) is important" [30].

None of the CEO statements spoke specifically about the systemic structures within their organizations that might be preventing them from incorporating the cultural competencies of their Black employees in their business processes. However, a couple of leaders did talk about how their organization is using diversity, in general, to connect with more diverse communities, and to elevate the economic conditions of diverse markets:

Equity and inclusion have been deeply rooted values since our founding. And they remain defining truths of who we are and what we do...Collectively, we've helped to support small businesses owned by people of color; create new job opportunities and build careers; amplify diverse voices to inspire and form; and provide resources to empower underserved communities...We recently expanded upon our decade-long efforts to close the digital equity gap with a \$1 billion commitment to reach an additional 50 million lowincome Americans (Brian L. Roberts, Chairman and CEO, Comcast NBC Universal).

We emphasize our sustainability commitments and ensure accountability... with our employees. Through a robust process of stakeholder engagement, we took a fresh look at our priority ESG topics and developed a materiality matrix that will help inform our sustainability strategies and initiatives...in 2020, we established our third set of five-year diversity goals (Kathy J. Warden, Chairman, CEO, President, Northrup Grumman).

None of the CEO statements indicated that these tech organization leaders encourage and listen specifically to their Black employees' experiences in the workplace and beyond. This was disheartening, as the literature is full of accounts of Black professionals working in predominantly white spaces unable to show up as their authentic selves [73-75]. In recent years, the Black Lives Matter movement has encouraged Black communities to fully, embrace themselves, but many remain scared to bring their authentic selves to work. Truth of the matter is Black employees are hurting. Since March 2020, many have been adjusting to virtual work, work-life balance demands, compounded by the pandemic and police brutality. While Black employees struggle to internalize the trauma of existing within predominantly white spaces, white leadership expect them to maintain performance and deliver results, as if everything is fine. However, today is a new day. More and more Black employees are beginning to stand up for themselves in workplaces across corporate America, because they are tired of doing what is expected of them when it produces the same results as not standing up for themselves. According to Ely \& Thomas [30] a white man can earn respect and sometimes even promotions for speaking up for himself, while Black men and women who do the same thing are viewed as being overly aggressive and are penalized. What usually happens is Black employees shutdown and become silent, or leave the organization. It's up to leaders to acknowledge the harm that policies, practices, processes, and work styles that Black employees experience in their organization and commit to learning from cultural differences to make a change and advocate for those without a voice.

\subsection{Make Cultural Differences a Resource for Learning}

Organizations shifting their workplace cultures to a learningand-effectiveness paradigm have an opportunity to draw upon lessons from cultural differences to let go of systemic practices and polices [30]. In 1996, Ely \& Thomas called upon leaders to learn from differences and create inclusive cultures where the perspectives and opinions of underrepresented employees could enhance work processes, products, services and policies, and challenge white employees to build authentic relationships with these colleagues. Then, in 2020, the authors, realizing that organizations had not progressed, set out to get serious about drawing corporate America's attention to leveraging cultural differences as a resource for learning. Even twentyone years later, the warning still remains true that if "leaders have created trust, begun to dismantle systems of discrimination and subordination, and embraced a broad range of styles...only in reaction to diversity-related crises - when discussions tend to be fraught and people's capacity to learn is diminished," the result is less action and symbolic discourse [30].

\subsection{Sub-Themes}

Leaders serious about learning from racial diversity need to leverage diversity statements to talk about their moral position on diversity, express how important it is to lead engaging, open conversations about race, and really listen to Black employees, letting their voices influence the behavior and culture of the organization. The tech companies in this study communicated a moral position to do the right thing and some leaders expressed personal desire to move towards inclusion. It is evident from Geoff Martha's CEO statement that he is "frustrated, and...angry" about George Floyd's murder and is committed to fighting racism and discrimination: "I won't tolerate it...I-we-must be better than that and that we will continue to give our time, our resources and our attention to make this better." It is also evident that Medtronic provides "Networks and ERGs" for diverse voices and he takes time to reaffirm company values to all employees: "Let's continue to respect and support all of our colleagues - no matter their race, gender or orientation." Raytheon Technologies's Gregory J. Hayes' CEO statement also acknowledge the death of Floyd as "the result of a reprehensible act" that calls for the organization "to respond clearly that racism, discrimination and hatred will not be tolerated." Hayes' statement suggests 
that Raytheon has created spaces as well "to understand experiences and perspectives that are different from our own. Complex issues raise difficult questions and conversations." Brian L. Roberts, Chairman and CEO, Comcast NBC Universal refers to Floyd's murder as "heartbreaking." Roberts' statement highlights how Comcasts' employees "amplify diverse voices to inspire and inform" and references networks and programs within the organization and community in which "employees support each other and come together with our partners to make our company and communities stronger and more reflective of the world we want it to be." Northrup Grumman's Kathy J. Warden's CEO statement was a lot more symbolic describing the events of 2020 as "the Covid-19 pandemic and call for social justice and unity." Warden's statement showed no personal empathy for the murder specifically. There was also no mention of specific spaces dedicated to diverse voices. However, Warden's statement did mention, Northrup Grumman's “Sustainability Report [which] reflects our Values - who we are and how we behave. Last year, we restated and reaffirmed those Values, clearly defining what we should expect from our company and from one another in an increasingly complex world. It is through living our Values that we collectively deliver on our strategy and commitments." The hope is that Northrup Grumman consulted with diverse employees, including their Black employees, when compiling data and information for the report, and that, the report is being made accessible and visible for all employees and external stakeholders. According to Searcy \& Buslovich [76], organizations should utilize their sustainability report as an internal tool to legitimate acceptable behavior, monitor and track progress of goals, as an instrument to engage employees, and as a recruitment and marketing tool to attract diverse employees and customers.

\subsection{Theoretical Implications}

The theory of diversity management [23] and the concept of corporate legitimacy theory [11] suggest that the research findings are problematic for U.S. tech companies. The CEO statements assessed in this study provided symbolic messages to both internal and external stakeholders on their commitment to lead diversity efforts of true behavioral change and cultural shifts. The leaders appeared to be doing more listening and talking than leading change at the time. The language used was simple 'window dressing', in terms of, giving the appearance that corporate practices reflect established norms and acceptable diversity practices, when it was unclear whether their current practices were inclusive [9, 19].

The researcher found considerable incongruence of the results of the content analysis with recommendations from the diversity management literature when examining whether these four tech CEO statements were successful in expressing their commitment to racial equity within the walls of their organizations. In fact, their statements were vague and did not refer to the racial composition of their companies at all, suggesting that these companies could still be in the initial stage of diversity management, according to Thomas and Ely [23] which is discrimination and fairness. However, since these organizations made Diversity Inc.'s Top 50 list, we can assume they are well past this diversity in representation phase.

Based on their ranking on the Top 50 list, these companies should reasonably be somewhere between the access and legitimacy paradigm and the learning and effectiveness approach to diversity management. The learning and effectiveness approach is a relatively new business case for diversity management that allows organizations to learn from conflict and diverse ways of thinking about work to redefine products, services, missions and best practices [8, 30]. According to Brinkerhoff [77], truly inclusive companies are committed to changing their diversity policies and programs to align to external stakeholder perceptions. This is important, as more organizations are moving towards strengthening their diversity policy statements in response to the Black Lives Matter movement.

\section{CONCLUSION}

As protests for change continue to rise across the U.S., it is clear that returning to business as usual will soon be a thing of the past. Black people and their allies have called out racism on the streets and organizational leaders will no longer be able to hide behind vague platitudes about behavioral and cultural change. Black employees, especially, want to see their leaders commit to action in terms of achieving racial equity in their workplaces. The CEO statements in the current sample do not include substantive language that talks about specific leadership initiatives, diversity training, supplier diversity programs, or even mentoring programs for Black employees. However, the statements do communicate beginning levels of leadership interest in building trust with Black people. Perhaps, this is partly due to an instinctual desire for CEOs to react to crises with aspirational appeals for moral legitimacy.

There is a new interest for organizations to offer policy statements that provide actual, diversity management practices that can change company-wide culture. Although this study identified many instances of symbolic elements, where organizations appeared to be committed to diversity, it is difficult to gauge how accurate these claims are. For example, none of these organizations included statistics on how diverse their company is or provided details about how inclusive it is becoming. This lack of information makes it difficult for stakeholders to form a real opinion about whether the diversity statement is legitimate. It is important to point out that substantive expressions, are not often found in corporate diversity statements, because they require companies to demonstrate significant changes in their diversity management efforts. Likewise, it is unclear whether the CEOs of this study have invested time in learning about how systems of privilege are oppressive and whether they have any interest in the shared organizational mission for learning and systemic change. These companies were either positioned within the 'Actively working against discrimination and subordination' or 'Embrace wide range of styles and voices' paradigms, with average to moderate levels of leadership commitment. Nonetheless, it is obvious that each leader cared enough to 
make racial diversity a priority for the moment and address their stakeholders.

This study identified four categories of diversity leadership communication practices used by the four CEO statements examined: build trust (talk about moral position); actively work against discrimination and subordination (express how important it is to lead engaging, open conversations about race), embrace wide range of styles and voices (communicate why really listening to the Black perspective is important to work), and make cultural differences a resource for learning (discuss a plan to learn from and allow racial differences to positively influence organizational behavior and culture).

This study contributes to the diversity literature by examining how organizations think about racial diversity and assessing which diversity messages have been adopted. The sample, drawn from the Diversity Inc. top-rated companies, provides a window into the racial justice statements used by some of the most successful tech companies in the U.S. Start-up tech companies can use these results as an indication that more attention needs to be given to the language of CEO statements in response to a racial crisis. To move forward, leaders must take the risk to prioritize the needs of Black employees to work with dignity of being their authentic selves and having their life experiences valued. This study revealed the importance of diversity of thought, in terms of including minority stakeholders in organizational decision-making, including giving them a voice in the shared values and mission of the organization.

\subsection{Implications for Research and Practice}

The sample of corporations used in this study was based on their national recognition by the 2021 Diversity Inc. Top 50 Companies for Diversity in regards to their commitment to diversity and organizational change. As such, it is obvious that these companies value diversity, but remains unclear whether their stakeholders understand what this distinction actually means. For this reason, it could be difficult for companies who are not widely known for their diversity management efforts outside of making this list to successfully appeal for moral legitimacy. The researcher ponders whether organizational leadership of the companies of this study should implement elements of their corporate diversity policy into their CEO statement to support their statements of commitment to diversity. Based on the current CEO statements, it is unclear whether the organizations of this study currently have a detailed plan to manage diversity or are taking any actions towards advancing inclusion.

Further research suggests exploring how stakeholders interpret U.S., CEO statements, in terms of, moral legitimacy. This study supports Singh and Point's [9] realization that "there are implications for researchers in the diversity field who hitherto have made general statements about diversity policies and the legitimacy that they may attract" (p. 33). Using their framework and these results, researchers can now be more critical regarding the lack of moral legitimacy that CEO diversity statements attract. Furthermore, the researcher suggests that it would also be interesting to add diversity policy statements as context to CEO statements, in terms of whether leadership messages would be perceived as offering more meaningful engagement with stakeholders and substantive expressions of how organizations actively manage, evaluate and measure diversity and inclusion success. The implications for human resource and diversity practitioners is that CEO statements should present a well-defined diversity strategy that aligns with business results, and discusses how the organization engages in inclusive diversity initiatives and practices [49]. Future research should investigate whether nonawardees of Diversity Inc.'s Top 50 Companies for Diversity, such as the plethora of private sector tech start-up companies springing up in Silicon Valley or the many GovTech newcomers, have similar or different diversity managementlegitimacy coordination. In conclusion, the strategy of looking at CEO statements through a diversity-legitimacy perspective is only one plausible step in making progress towards establishing a standard for U.S. corporate diversity statements.

\section{REFERENCES}

[1] Hoyer, W.D., Kroschke, M., Schmitt, B., Kraume, K. and Shankar, V. (2020). Transforming the customer experience through new technologies. Journal of Interactive Marketing, 51, $57-71$.

[2] Tai, D.B.G., Shah, A., Doubeni, C.A., Sia, I.G. \& Wieland, M.L. (2021). The disproportionate impact of COVID-19 on racial and ethnic minorities in the United States. Clinical Infectious Diseases, 72(4), 703-706.

[3] United States Department of Labor, Bureau of Labor Statistics (2021). Economic new release: Employment situation summaryJuly 2021. (USDL Bulletin No. 21-1434).

[4] Singh, V. \& Point, S. (2006). (Re) presentations of gender and ethnicity in diversity statements on European company websites. Journal of Business Ethics, 68(4), 363-379.

[5] Diversity Inc. (2021). 2021 Top 50 companies for diversity list.

[6] Sung, S.Y. \& Choi, J.N. (2021). Contingent effects of workforce diversity on firm innovation: High-tech industry and market turbulence as critical environmental contingencies. The International Journal of Human Resource Management, 32(9), 1986-2021.

[7] McGee, E.O. \& Bentley, L. (2017). The troubled success of Black women in STEM. Cognition and Instruction, 35(4), 265289.

[8] Ely, R.J. \& Thomas, D.A. (2001). Cultural diversity at work: The effect of diversity perspectives on work group processes and outcomes. Administrative Science Quarterly, 46(2), 229-273.

[9] Singh, V. \& Point, S. (2009). Diversity statements for leveraging organizational legitimacy. International Management, 13(2), 2334.

[10] McKay, P.F. \& Avery, D.R. (2006). What has race got to do with it? Unraveling the role of racio-ethnicity in job seekers' reactions to site visits. Personnel Psychology, 59(2), 395-429.

[11] Suchman, M.C. (1995). Managing legitimacy: Strategic and institutional approaches. Academy of Management Review, 20(3), 571-610.

[12] Leslie, L.M. (2019). Diversity initiative effectiveness: A typological theory of unintended consequences. Academy of Management Review, 44(3), 538-563. 
[13] Taneja, S., Pryor, M.G. \& Oyler, J. (2012). Empowerment and gender equality: The retention and promotion of women in the workforce. Journal of Business Diversity, 12(3), 43-53.

[14] Scott, W.R. (2008). Approaching adulthood: The maturing of institutional theory. Theory and Society, 37(5), 427.

[15] Hyatt, D.G. \& Berente, N. (2017). Substantive or symbolic environmental strategies? Effects of external and internal normative stakeholder pressures. Business Strategy and the Environment, 26(8), 1212-1234.

[16] Ng, E.S. \& Sears, G.J. (2012). CEO leadership styles and the implementation of organizational diversity practices: Moderating effects of social values and age. Journal of Business Ethics, 105(1), 41-52.

[17] Scott, W.R., Ruef, M., Mendel, P.J. \& Caronna, C.A. (2000). Institutional change and healthcare organizations. Chicago: The University of Chicago Press.

[18] Hon, L.C. \& Brunner, B. (2000). Diversity issues and public relations. Journal of Public Relations Research, 12(4), 309-340.

[19] Ashforth, B. E., \& Gibbs, B. W. (1990). The double-edge of organizational legitimation. Organization science, 1(2), 177-194.

[20] Saxena, A. (2014). Workforce diversity: A key to improve productivity. Procedia Economics and Finance, 11, 76-85.

[21] Liao, H., Chuang, A. \& Joshi, A. (2008). Perceived deep-level dissimilarity: Personality antecedents and impact of overall job attitude, helping, work withdrawal, and turnover. Organizational Behavior and Human Decision Processes, 106(2), 106-124.

[22] Cox, T.H. \& Blake, S. (1991). Managing cultural diversity: Implications for organizational competitiveness. Academy of Management Perspectives, 5(3), 45-56.

[23] Thomas, D.A. \& Ely, R.J. (1996). Making differences matter. Harvard Business Review, 74(5), 1-13.

[24] Heijltjes, M. Olie, R. \& Glunk, U. (2003). Internationalization of top management teams in Europe. European Management Journal, 21(1), 89-97.

[25] Shore, L.M., Randel, A.E., Chung, B.G., Dean, M.A., Ehrhart, K.H. \& Singh, G. (2011). Inclusion and diversity in work groups: A review and model for future research. Journal of Management, 37(4), 1262-1289.

[26] Chua, P.K. \& Mazmanian, M. (2020). Are you one of us? Current hiring practices suggest the potential for class biases in large tech companies. Proceedings of the ACM on Human Computer Interaction, 4(CSCW2), 1-20.

[27] Houser, A. (2019). Can AI solve the diversity problem in the tech industry: Mitigating noise and bias in employment decisionmaking. Stan Tech L. Rev., 22, 290-354.

[28] Herring, C. (2009). Does diversity pay? Race, gender, and the business case for diversity. American Sociological Review, 74(2), 208-224.

[29] Mitsakis, F. V. 2019. "Human Resource Development (HRD) Resilience: A New 'Success Element' of Organizational Resilience?" Human Resource Development International, 23(3), 321-328.

[30] Ely, R.J. \& Thomas, D.A. (2020). Getting Serious about diversity. Harvard Business Review, 98(6), 114-122.

[31] Wynn, A.T. (2010). Pathways toward change: Ideologies and gender equality in a Silicon Valley technology company. Gender \& Society, 34(1), 106-130.
[32] Kalev, Dobbin \& Kelly (2006). Best practices or best guesses? Assessing the efficacy of corporate affirmative action and diversity policies. American Sociological Review, 71, 589-617.

[33] Algeria, S.N. (2020). What do we mean by broadening participation? Race, inequality, and diversity in tech work. Sociology Compass, 14(6), 12793.

[34] Njoku, A., Ahmed, Y. \& Bolaji, B. (2020). Police brutality against Blacks in the United States and ensuring protests: Implications for social distancing and Black health during Covid-19. Journal of Human Behavior in the Social Environment, 31(1-4), 262-270.

[35] Castelló, I., \& Lozano, J. M. (2011). Searching for new forms of legitimacy through corporate responsibility rhetoric. Journal of Business Ethics, 100(1), 11-29.

[36] Chen, J. C., \& Roberts, R. W. (2010). Toward a more coherent understanding of the organization-society relationship: A theoretical consideration for social and environmental accounting research. Journal of business ethics, 97(4), 651-665.

[37] Crane, A. \& Matten, D. (2020). Covid-19 and the future of CSR Research. Journal of Management Studies, 58(1), 280-284.

[38] Pless, N. (2007). Understanding responsible leadership: Role identity and motivational drivers. Journal of Business Ethics, 74(4), 437-456

[39] Palazzo, G. \& Scherer, A.G. (2006). Corporate legitimacy as deliberation: A communicative framework. Journal of Business Ethics, 66(1), 71-88.

[40] Koehn, N. (2020). Real leaders are forged in crisis. Harvard Business Review, 3, 2-6.

[41] Pless, N. \& Maak, T. (2009). Responsible leaders as agents of world benefit: Learnings from "Project Ulysses". Journal of Business Ethics, 85(1), 59-71.

[42] Veil, S. R. (2020). "Revisiting the Best Practices in Risk and Crisis Communication: A Multi Case Analysis." In The Handbook of Applied Communication Research, edited by $\mathrm{H}$. Dan O'Hair, 377-396. New York: John Wiley \& Sons.

[43] Gilbreath, B., and M. U. Montesino. 2006. "Expanding the HRD Role: Improving Employee Well-being and Organizational Performance." Human Resource Development International, 9(4): 563-571.

[44] Point, S. \& Singh, V. (2003). Defining and dimensionalising diversity: Evidence from corporate websites across Europe. European Management Journal, 21(6), 750-761.

[45] Uysal, N. (2013). Shifting the paradigm: Diversity communication on corporate websites. Public Relations Journal, 7(2), 8-36.

[46] Moon, N. (2007). The fatal flaws of diversity and the business case for ethnic minorities. Work, Employment and Society, 21(4), 773-784.

[47] Robinson, G. \& Dechant, K. (1997). Building a business case for diversity. Academy of Management Perspectives, 11(3), 21-31

[48] Shore, L.M., Chung-Herrera, B.G., Dean, M.A., Ehrhart, K.H., Jung, D.I, Randel, et al. (2009). Diversity in organizations: Where are we now and where are we going? Human Resource Management Review, 19(2), 117-133.

[49] Jayne, M. \& Dipboye, R. (2004). Leveraging diversity to improve business performance: Research findings and recommendations for organizations. Human Resource Management, 43(4), 409-424. 
[50] Gilbert, J.A. \& Ivancevich, J.M. (2000). Valuing diversity: A tale of two organizations. Academy of Management Perspectives, 14(1), 93-105.

[51] Rawlins, B. (2008). Give the emperor a mirror: Toward developing a stakeholder measurement of organizational transparency. Journal of Public Relations Research, 21(1), 7199.

[52] Creswell, J. (2009). Mapping the field of mixed methods research. Journal of Mixed Methods Research, 3(2), 95-108.

[53] Krippendorff, K. (2004). Reliability in content analysis: Some common misconceptions and recommendations. Human Communication Research, 30(3), 411-433.

[54] Freelon, D. (2010). ReCal: Itercoder reliability calculation as a web service. International Journal of Internet Service, 5(1), 2033.

[55] Hammond, W.P. \& Mattis, J.S. (2005). Being a man about it: Manhood meaning among African American Men. Psychology of Men \& Masculinity, 62(2), 114-126.

[56] Cook, A. \& Glass, C. (2014). Above the glass ceiling: When are women and racial/ethnic minorities promoted to CEO? Strategic Management Journal, 35, 1080-1089.

[57] Findler, L., Wind, L.H. \& Barak, M.E.M. (2007). The challenge of workforce management in global society: Modelling the relationship between diversity, inclusion, organizational culture, and employee well-being, job-satisfaction and organizational commitment. Administration in Social Work, 31(3), 63-94.

[58] Wasserman, I.C., Gallegos, P.V. \& Ferdman, B.M. (2008). Dancing with resistance: Leadership challenges in fostering a culture of inclusion. In K.M. Thomas \& K.M. Thomas (Eds.), Diversity Resistance in Organizations, (pp. 175-200). New York, NY: Taylor\& Francis Group, Lawrence Erlbaum Associates.

[59] Ng, E.S. \& Burke, R.J. (2005). Person-organization fit and the war for talent: Does diversity management make a difference? The International Journal of Human Resource Management, 16(7), 1195-1210.

[60] Avery, D.R. \& McKay, P.F. (2006). Target practice: An organizational impression management approach to attracting minority and female job applicants. Personnel Psychology, 59, 157-187.

[61] Rau, B.L. and Hyland, M.M. (2003). Corporate teamwork and diversity statement in college recruitment brochures: Effects on attraction. Journal of Applied Social Psychology, 33, 2465-2492.

[62] Mor Barak, M.E. (2000). The inclusive workplace: An ecosystems approach to diversity management. Social Work, 45(4), 339-353.

[63] Bartkus, B.R. \& Glassman, M. (2008). Do firms practice what they preach? The relationship between mission statements and stakeholder management. Journal of Business Ethics, 83(2), 207216.

[64] Parent, J.D. \& Lovelace, K.J. (2018). Employee engagement, positive organizational culture and individual adaptability. On The Horizon- The Strategic Planning Resource for Education Professionals, 26(3), 206-214.

[65] Feyes, E. (2018). Leadership and the promotion of diversity in the work force and beyond. Leadership in Healthcare and Public Health.
[66] Agarwal, U.A. (2014). Linking justice, trust and innovative work behavior to work engagement. Personnel Review, 43(1), 41-73.

[67] Frazier, M.L., Fainshmidt, S., Klinger, R.L., Pezeshkan, A. and Vracheva, V. (2017). Psychological safety: A meta-analytic review and extension. Personnel Psychology, 70(1), 113-165.

[68] Zhang, A.Y., Tsui, A.S., Song, L.J., Li, C. and Jia, L. (2008). How do I trust thee? The employee-organization relationship, supervisory support, and middle manager trust in the organization. Human Resource Management: Published in Cooperation with the School of Business Administration, The University of Michigan and in alliance with the Society of Human Resource Management, 47(1), 111-132.

[69] Javed, B., Naqvi, S.M.M.R., Khan, A.K, Arjoon, S. \& Tayyeb, H.H. (2019). Impact of inclusive leadership on innovative work behavior: The role of psychological safety. Journal of Management \& Organization, 25(1), 117-135.

[70] Lockwood, N.R. (2007). Leveraging employee engagement for competitive advantage. Society for Human Resource Management Research Quarterly, 1(1), 1-12.

[71] Meek, V.L. (1988). Organizational culture: Origins and weaknesses. Organization Studies, 9(4), 453-473.

[72] Singh, B., Winkel, D.E. \& Selvarajan, T.T. (2013). Managing diversity at work: Does psychological safety hold the key to racial differences in employee performance? Journal of Occupational and Organizational Psychology, 86(2), 242-253.

[73] Carter, D. \& Peters, T. (2016). The underrepresentation of African American women in executive leadership: What's getting in the way. Journal of Business Studies Quarterly, 7(4), 115-134.

[74] Holder, A., Jackson, M.A. \& Ponterotto, J.G. (2015). Racial microaggression experiences and coping strategies of Black women in corporate leadership. Qualitative Psychology, 2(2), 164-180.

[75] Wingfield, A.H. (2010). Are some emotions marked Whites only? Racialized feeling rules in professional workplaces. Social Problems, 57(2), 251-268.

[76] Searcy, C. \& Buslovich, R. (2014). Corporate perspectives on the development and use of sustainability reports. Journal of Business and Ethics, 121(2), 149-169.

[77] Brinkerhoff, D. (2005). Organizational legitimacy, capacity and capacity development. European Center for Development Policy Management.

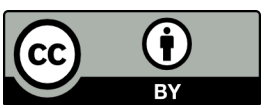

(C) 2021 by the Dr. Monica Valentine. Submitted for possible open access publication under the terms and conditions of the Creative Commons Attribution (CC BY) license (http://creativecommons.org/licenses/by/4.0/). 